\title{
Does Surgical Hip Dislocation and Periacetabular Osteotomy Improve Pain in Patients With Perthes-like Deformities and Acetabular Dysplasia?
}

\author{
John C. Clohisy MD, Jeffrey J. Nepple MD, James R. Ross MD, \\ Gail Pashos BS, Perry L. Schoenecker MD
}

Published online: 6 January 2015

(C) The Association of Bone and Joint Surgeons (R 2014

\begin{abstract}
Background Patients with symptomatic residual Pertheslike deformities may present with a combination of structural abnormalities including a large aspheric femoral head, short and wide femoral neck, high greater trochanter, and acetabular dysplasia. Sometimes, the hip is further compromised by concurrent symptomatic femoroacetabular impingement (FAI) (proximal femoral deformities) and structural instability (acetabular dysplasia).

Questions/purposes We therefore sought to characterize (1) the intraoperative findings; (2) radiographic correction; and (3) early patient-reported outcomes, complications, and failures of treating complex Perthes-like hip deformities with combined surgical dislocation and periacetabular osteotomy (PAO).
\end{abstract}

Each author certifies that he or she, or a member of his or her immediate family, has no funding or commercial associations (eg, consultancies, stock ownership, equity interest, patent/licensing arrangements, etc) that might pose a conflict of interest in connection with the submitted article.

All ICMJE Conflict of Interest Forms for authors and Clinical Orthopaedics and Related Research ${ }^{\circledR}$ editors and board members are on file with the publication and can be viewed on request.

Each author certifies that his or her institution approved the human protocol for this investigation, that all investigations were conducted in conformity with the ethical principles of research, and that informed consent for participation in the study was obtained. This work was performed at Washington University School of Medicine, St Louis, MO, USA.

J. C. Clohisy ( (), J. J. Nepple, G. Pashos, P. L. Schoenecker Department of Orthopaedic Surgery, Washington University School of Medicine, 660 South Euclid Avenue, Campus Box 8233, St Louis, MO 63110, USA

e-mail: clohisyj@wudosis.wustl.edu

J. R. Ross

University of Michigan, Ann Arbor, MI, USA
Methods We performed 694 hip preservation procedures between November 2006 and August 2010. Of these, 46 had residual Perthes-like hip deformities, defined as proximal deformity consistent with residual Perthes and a history of Perthes disease or treatment of pediatric hip dysplasia. Of these, we report on 16 patients (16 hips) with residual Perthes-like hip deformities and associated acetabular dysplasia (structural instability, defined as radiographic evidence of acetabular dysplasia with intraoperative confirmation of instability). These 16 patients were treated with a combined surgical hip dislocation to comprehensively address intraarticular and extraarticular sources of FAI and PAO to address structural instability and were analyzed at a minimum 24-month followup (median, 40 months; range, 2478 months). No patients in this series were lost to followup. Ten patients' hips had previous surgical treatment, including six with previous osteotomy. Operative findings were extracted from standardized prospectively collected intraoperative data collection forms. Radiographic correction was evaluated with established methods (lateral center-edge angle, anterior center-edge angle, acetabular inclination, center-to-trochanter distance) and clinical outcomes were measured with the modified Harris hip score (mHHS) as well as by prospectively recorded data on patient complications and followup.

Results Acetabular labrochondral abnormalities included labral hypertrophy in all hips and labral and/or articular cartilage lesions requiring treatment in 13 hips. Radiographic analysis demonstrated consistent radiographic correction. The median preoperative mHHS improved from 64 to 92 at a median followup of 40 months $(\mathrm{p}<0.001)$. Fourteen patients (14 hips) had a good or excellent clinical result. Two patients (two hips) were classified as failures based on mHHS less than $70(\mathrm{n}=1)$ or conversion to total hip arthroplasty $(\mathrm{n}=1)$. 
Conclusions Combined surgical hip dislocation and PAO provides major deformity correction in Perthes-like hip deformities with associated acetabular dysplasia. Early clinical results suggest this technique is safe and effective. Long-term studies are needed to determine if improved long-term outcomes are associated with comprehensive deformity correction.

Level of Evidence Level IV, therapeutic study.

\section{Introduction}

Residual Perthes-like deformities can cause hip pain, functional limitations, and eventual secondary osteoarthritis $[4,16,23]$. Femoral deformities generally including a large aspheric femoral head, a short, wide femoral neck, coxa vara, and a high greater trochanter [24, 32, 33], whereas acetabular dysplasia or abnormal version may be present $[6,10,18,20,21,33]$. Femoroacetabular impingement (FAI) in residual Perthes-like deformities is complex and may include variable components of intraarticular and extraarticular abutment. Secondary acetabular dysplasia can be a source of joint instability and can result in acetabular rim overload and concurrent labrochondral complex degeneration [29]. Together these structural abnormalities create a complex pathomechanical environment that can cause FAI, structural instability (acetabular dysplasia), or both [10, 25]. Long-term studies have demonstrated the development of osteoarthritis by middle age in $20 \%$ to $54 \%$ of patients with residual Perthes deformities $[19,22,38]$. Because of the variability in presentation, the treatment of residual Perthes-like deformities is complex.

Young adult and adolescent patients who present with symptomatic Perthes-like deformities are potential candidates for joint preservation surgery, yet there is relatively little information regarding optimal treatment strategies $[3,6,10,13,35]$. Treatment options for addressing the femoral-sided deformity most commonly include proximal femoral osteotomy or surgical dislocation (generally with femoral osteochondroplasty). Surgical dislocation allows for trochanteric advancement and relative femoral neck lengthening to improve pathomechanics of the hip and prevent trochanteric impingement $[1,14,15]$. This approach enables wide exposure of the proximal femur and acetabular rim allowing dynamic examination and treatment of associated intraarticular abnormalities $[1,3,12,13$, 28, 30]. Periacetabular osteotomy (PAO) can correct associated structural instability when needed $[6,9,11,12]$. We have previously reported PAO variably combined with a proximal femoral osteotomy to have excellent short-term outcomes [9, 12]. As our experience treating residual Perthes-like hip deformities has expanded, we have refined our surgical strategy. For deformities with concurrent FAI and acetabular dysplasia (structural instability), we presently use a combined surgical hip dislocation and PAO [11]. However, few studies have evaluated the results of treatment of Perthes-like hip disorders with this surgical strategy.

We therefore sought to characterize (1) the intraoperative findings; (2) radiographic correction; and (3) early patient-reported outcomes, complications, and failures of treating complex Perthes-like hip deformities with combined surgical dislocation and PAO.

\section{Materials and Methods}

We performed a review of one of the senior authors' (JCC) database of 694 hip preservation cases performed between November 2006 and August 2010. Institutional review board approval was obtained for the study. Sixteen patients (16 hips) treated with a combined surgical dislocation to address intra- and extraarticular FAI and PAO for Pertheslike deformities with structural instability were identified (Fig. 1). We defined a Perthes-like deformity as proximal femoral deformity consistent with residual Perthes (highriding greater trochanter, coxa magna, coxa breva) and a history of Perthes disease or sequelae of the treatment of developmental dysplasia of the hip with subsequent avascular necrosis. We defined structural instability in this context as radiographic evidence of acetabular dysplasia with intraoperative confirmation of instability. Preoperative assessment included clinical presentation, physical examination, and radiographic assessment, which suggested underlying dysplasia. The hip was assessed for dynamic instability during surgical hip dislocation, which was defined as subluxation of the hip in any one of three positions $\left(10^{\circ}\right.$ extension $/ 15^{\circ}$ external rotation; $45^{\circ}$ flexion/ $20^{\circ}$ adduction $/ 30^{\circ}$ internal rotation; $90^{\circ}$ flexion/neutral

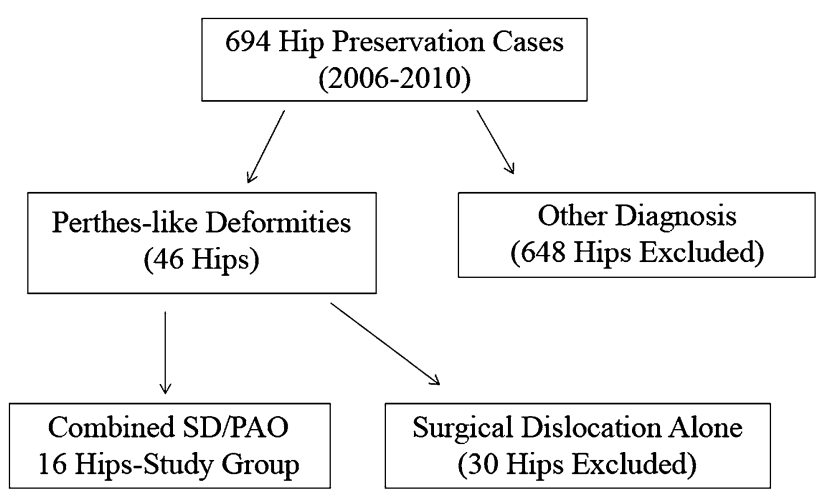

Fig. 1 A flowchart demonstrates the study patient population. $\mathrm{SD}=$ surgical dislocation. 
rotation). During the study period, the indications for this combined approach included symptomatic Perthes-like deformities and structural instability without radiographic evidence of significant osteoarthritis. Symptomatic patients were considered for surgical treatment after demonstrating failure to improve with at least 3 months of nonoperative treatment (activity modification, physical therapy, and nonsteroidal antiinflammatory medications). Hips with joint space loss of $50 \%$ or more were not eligible for hip preservation surgery. The senior author (JCC) did not use other surgical approaches to treat this constellation of findings during this period. Over this same time interval, 30 Perthes-like hips without associated structural instability were treated with surgical dislocation alone for FAI and were excluded from this study. Preoperative imaging generally included AP pelvis, false profile, frog lateral, and von Rosen radiographs as well as MRI. Preoperative characterization of femoral version was not obtained during this study period but is now routinely performed with low-dose CT. Patients were generally maintained toe-touch weightbearing for 4 weeks postoperatively. All eligible patients had at least 24-month followup (median, 40 months; range, 24-78 months). No patients were lost to followup.

Surgical treatment included surgical hip dislocation in all patients to address intraarticular pathology, intraarticular/extraarticular impingement, and proximal femoral deformity. The median estimated blood loss was $1250 \mathrm{~mL}$ and median surgical time 352 minutes. Staged surgical dislocation and PAO were performed in three hips, whereas 13 hips underwent simultaneous procedures. Surgical dislocation was performed with femoral head-neck osteochondroplasty, trochanteric advancement, and relative femoral neck lengthening in all cases. Treatment of two hips also included a valgus proximal femoral osteotomy for inadequate hip ROM (particularly abduction) to tolerate a subsequent PAO. PAO was then performed in all cases for radiographic evidence of acetabular dysplasia associated with (1) hip flexion of at least $90^{\circ}$ and abduction of at least $20^{\circ}$; (2) excellent or good congruity on intraoperative functional radiographs; and (3) dynamic instability present intraoperatively [28]. A hip was considered dynamically unstable if the intraoperative assessment revealed femoral head subluxation or dislocation with passive, functional ROM as described previously.

Eight patients (eight hips) were male and eight patients (eight hips) were female. The average age of patients at surgery was 22 years (range, 14-36 years). The minimum followup was 24 months (median, 40 months; range, 2478 months). The mean body mass index of the cohort was $26 \mathrm{~kg} / \mathrm{m}^{2}$ (range, $18-33 \mathrm{~kg} / \mathrm{m}^{2}$ ). The residual hip deformity was secondary to Perthes disease in 14 hip and developmental dysplasia of the hip with iatrogenic femoral head necrosis in two hips. Ten patients (10 hips) had previous surgical treatment for the involved hip. Six hips had undergone prior osteotomy surgery including three proximal femoral, one trochanteric, and two pelvic osteotomies. Three additional hips had other treatments including one with an adductor tenotomy and two with bracing. One patient had previous excision of a proximal femoral osteochondroma. A case example is shown (Fig. 2).

Radiographic evaluation was performed by a single reader (JRR) as previously published [29] and included measurement of lateral center-edge angle (LCEA) [37], acetabular inclination (AI) [36], acetabular head index (AHI) [18], and center-trochanter distance (CTD) [26] on preoperative and postoperative AP pelvis radiographs. Anterior center-edge angle (ACEA) [36] was measured on false profile radiographs. The modified Stulberg classification [17,33] was determined based on preoperative AP pelvis and frog-leg lateral radiographs. Class II hips were defined as spherical with a larger-than-normal femoral head, short femoral neck, and abnormally steep acetabulum. Class III hips were defined as nonspherical with an ovoid, mushroom shape but not flat. Class IV hips were defined as flat femoral head and acetabulum. Class V hips were defined as flat femoral head and normal acetabulum. For all measurements, the femoral head center of aspheric femoral heads was determined by the intersection of the largest and smallest diameters of the femoral head [29]. To assess the intraobserver reliability of these radiographic measurements, 10 radiographs were remeasured and showed intraclass correlation coefficients of 0.98 for AI, 0.99 for LCEA, 1.0 for ACEA, 0 for CTD, and 0.98 for AHI and kappa values of 1.0 for osteoarthritis grade and Stulberg class [11]. The degree of osteoarthritis on each radiograph was classified using a modified Tönnis classification [29], which excludes the assessment of femoral head sphericity from the original Tönnis classification [36].

Modified Stulberg classification included four Class 2, seven Class 3, three Class 4, and two Class 5 hips. Preoperative Tönnis osteoarthritis grades were 0 in six hips, 1 in nine hips, and 2 in one hip. The median preoperative LCEA was $13^{\circ}$, ACEA was $3^{\circ}$, and AI $23^{\circ}$. The median preoperative CTD was $-24 \mathrm{~mm}$ (range, -55 to $-8 \mathrm{~mm}$ ).

Intraoperative pathology was prospectively recorded with a standardized data collection tool [5, 8]. Disease location was documented using a clockface classification standardized to the right hip (3:00 anterior, 12:00 superior) [5]. Patient-reported pain, function, and activity were measured with the modified Harris hip score (HHS) and UCLA activity score. Preoperative and postoperative HHS were available on all patients, whereas the UCLA activity score was available preoperatively and postoperatively in 14 of 16 patients. ROM was measured by one of the senior authors (JCC) [27]. 

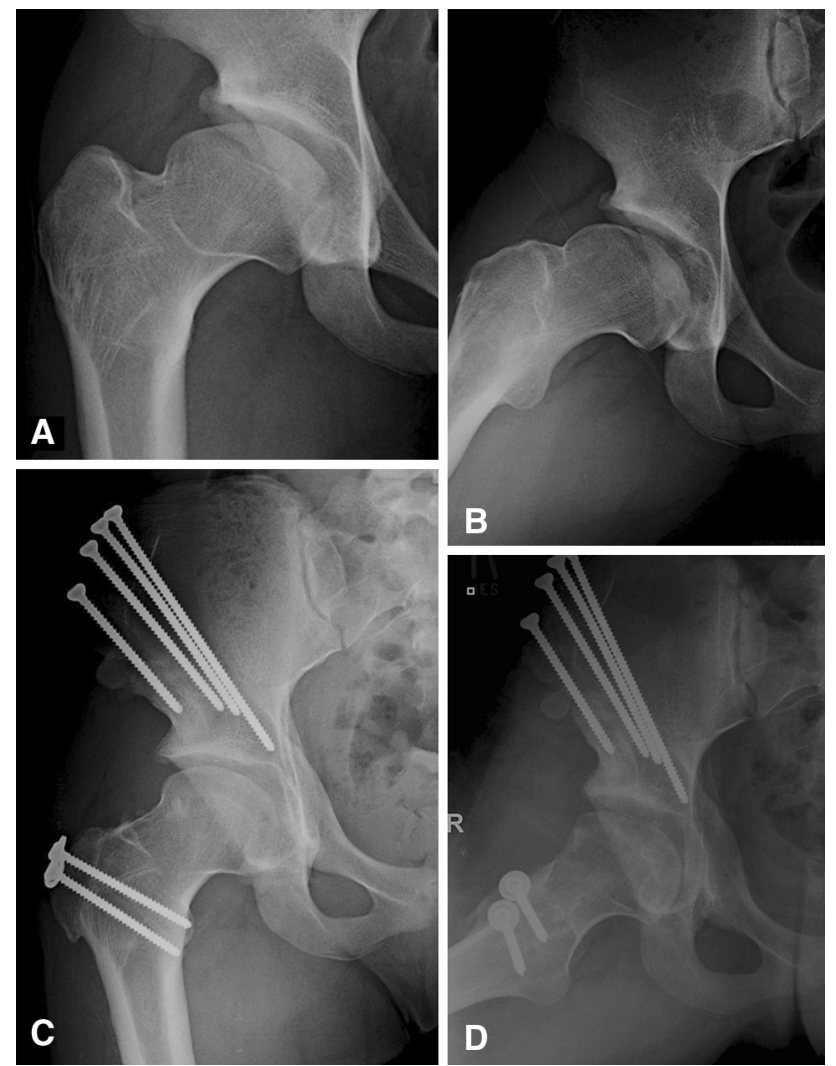

Fig. 2A-D A Perthes-like hip deformity correction with combined periacetabular osteotomy and surgical dislocation in a 17-year-old girl with persistent right hip symptoms is shown. The preoperative AP pelvis (cropped image) (A) demonstrates a Perthes-like deformity of the proximal femur with an aspheric femoral head, wide femoral neck, and high greater trochanter. There is secondary acetabular dysplasia with retroversion. The frog-lateral view (B) accentuates the asphericity of the femoral head and the wide femoral head. Postoperative radiographs (AP pelvis, cropped image $[\mathbf{C}]$ and froglateral $[\mathbf{D}])$ taken 1 year after surgery demonstrate excellent bony deformity correction. A surgical dislocation with femoral head reshaping, relative neck lengthening, and trochanteric advancement was performed. The hip was judged to be unstable at the time of surgery during dynamic examination and treated with combined surgical dislocation and PAO. The patient has an excellent result at most recent followup of 2 years with a HHS of 92 .

Hips were considered clinical failures if requiring THA or if postoperative HHS at followup was $<70$. Statistical analysis included comparisons of preoperative and postoperative parameters using Student's t-test. The association between preoperative parameters and final HHS was investigated using the Student's t-test and chi-square test.

\section{Results}

Intraoperative Findings

All hips demonstrated intraoperative dynamic subluxation during examination consistent with structural instability.
Table 1. Intraarticular findings in Perthes-like hip deformities

\begin{tabular}{lc}
\hline Intraarticular findings & Number \\
\hline Femoral head chondral lesions & 9 \\
Partial-thickness chondromalacia & 5 \\
Stable osteochondral lesion & 4 \\
Acetabular chondral lesions & 6 \\
Full-thickness flap/defect & 3 \\
Partial-thickness chondromalacia & 3 \\
Acetabular labral damage & 13 \\
Degeneration without detachment & 6 \\
Detachment & 7 \\
\hline
\end{tabular}

Intraarticular pathology was present in all hips in this series. Acetabular labrochondral pathology was present and treated in 13 hips, including six hips with labral repair and six hips with partial labral resection (Table 1). The acetabular labrum was uniformly noted to be hypertrophied. Three patients had labral detachments of at least $30 \mathrm{~mm}$ in length. Six labral tears extended anteriorly from the 12:00 position, including three tears that extended to the 3:00 anterior position. Four additional tears were located in the anterosuperior acetabulum (1:00-3:00). Two hips had acetabular rim cartilage flaps or defects, which were treated with microfracture (both 12:00-2:00 position). One hip underwent isolated débridement of a $3 \times 3-\mathrm{mm}$ acetabular rim defect. Three had acetabular rim malacia extending 20 to $30 \mathrm{~mm}$ anteriorly from the 12:00 position that did not require treatment. Nine hips had articular cartilage lesions on the weightbearing femoral head including four patients with full-thickness femoral head osteochondral lesions that were stable to probing and did not require treatment. An additional five hips had diffuse malacia about the weightbearing femoral head.

\section{Radiographic Correction}

Radiographic parameters of hip morphology all improved markedly after the PAO (Table 2). The median postoperative LCEA was $32^{\circ}$, ACEA $33^{\circ}$, and AI $7^{\circ}$. The CTD significantly decreased to a median of $-6 \mathrm{~mm}(\mathrm{p}=0.002)$, reflecting a median distalization of the greater trochanter of $18 \mathrm{~mm}$.

\section{Clinical Outcomes, Complications, and Reoperations}

Clinical improvements were seen in 14 of the 16 patients. The median mHHS improved from 64 preoperatively to 
Table 2. Changes in radiographic parameters from pre- to postoperatively

\begin{tabular}{|c|c|c|c|}
\hline \multirow[t]{2}{*}{ Radiographic parameter } & Preoperative & Postoperative & \multirow{2}{*}{$\begin{array}{l}\mathrm{p} \\
\text { value: }\end{array}$} \\
\hline & $\begin{array}{l}\text { Mean Median } \\
\text { (range) }\end{array}$ & $\begin{array}{l}\text { Mean Median } \\
\text { (range) }\end{array}$ & \\
\hline LCEA & $\begin{array}{l}12^{\circ} \quad 13^{\circ} \\
\left(2^{\circ}-34^{\circ}\right)\end{array}$ & $\begin{array}{l}32^{\circ} \quad 32^{\circ} \\
\left(20^{\circ}-42^{\circ}\right)\end{array}$ & 0.001 \\
\hline ACEA & $\begin{array}{l}3^{\circ} 3^{\circ} \\
\left(-32^{\circ} \text { to } 40^{\circ}\right)\end{array}$ & $\begin{array}{l}32^{\circ} \quad 33^{\circ} \\
\left(19^{\circ}-47^{\circ}\right)\end{array}$ & 0.001 \\
\hline $\begin{array}{l}\text { Acetabular } \\
\text { inclination }\end{array}$ & $\begin{array}{l}23^{\circ} \quad 23^{\circ} \\
\left(11^{\circ}-35^{\circ}\right)\end{array}$ & $\begin{array}{l}6^{\circ} \quad 7^{\circ} \\
\left(0^{\circ}-16^{\circ}\right)\end{array}$ & 0.001 \\
\hline $\begin{array}{l}\text { Center-to-trochanter } \\
\text { distance }(\mathrm{mm})\end{array}$ & $\begin{array}{l}-24-24 \\
(-55 \text { to }-8)\end{array}$ & $\begin{array}{l}-9 \quad-6 \\
(-34 \text { to }+15)\end{array}$ & 0.002 \\
\hline Extrusion index & $\begin{array}{l}65 \% \\
(53 \%-95 \%)\end{array}$ & $\begin{array}{l}92 \% \quad 93 \% \\
(57 \%-100 \%)\end{array}$ & 0.001 \\
\hline
\end{tabular}

* Wilcoxon signed ranks test; LCEA = lateral center-edge angle; $\mathrm{ACEA}=$ anterior center-edge angle.

Table 3. Summary of Harris hip scores and pain/limp subscores

\begin{tabular}{llll}
\hline Harris hip scores & \multicolumn{3}{l}{ Postoperative } \\
\hline Preoperative & & $90-100$ & 12 \\
\hline $90-100$ & 1 & $80-89.9$ & 1 \\
$80-89.9$ & 2 & $70-79.9$ & 1 \\
$70-79.9$ & 13 & $<70$ & 2 \\
$<70$ & 62 & Average & 87 \\
Average & 64 & Median & 93 \\
Median & $37-81$ & Range & $39-100$ \\
Range & & &
\end{tabular}

Harris hip pain scores

\begin{tabular}{llll}
\hline Preoperative & & Postoperative \\
\hline None & 0 & None & 6 \\
Slight & 0 & Slight & 6 \\
Mild & 2 & Mild & 2 \\
Moderate & 9 & Moderate & 0 \\
Marked & 5 & Marked & 2 \\
Disabling & 0 & Disabling & 0
\end{tabular}

Harris hip limp scores

\begin{tabular}{llll}
\hline Preoperative & & Postoperative \\
\hline None & 0 & None & 5 \\
Slight & 8 & Slight & 9 \\
Moderate & 7 & Moderate & 2 \\
Severe & 0 & Severe & 0 \\
Unable & 1 & Unable & 0 \\
\hline
\end{tabular}

92 postoperatively $(\mathrm{p}<0.001)$ (Table 3$)$. The mHHS improved a median of 28 points. Thirteen patients had HHS $<70$ preoperatively. Two patients had postoperative
HHS $<70$ (40 and 42) and were considered failures. The median postoperative HHS in the remaining 14 patients was 94. There was no change in UCLA activity score observed at latest followup (median of 9 out of 10, both before and after surgery; range, $2-10$ and $4-10$, respectively; $\mathrm{p}=0.578$ ). Postoperatively eight patients had a UCLA score of 9 or 10. Clinical hip ROM was relatively maintained postoperatively. Preoperative hip flexion averaged $94^{\circ}$ (range, $80^{\circ}-100^{\circ}$ ), and postoperative hip flexion averaged $90^{\circ}$. Preoperative hip abduction averaged $23^{\circ}$ (range, $10^{\circ}-40^{\circ}$ ), whereas postoperative averaged $28^{\circ}$ (range, $15^{\circ}-40^{\circ}$ ). Internal rotation in flexion averaged $16^{\circ}$ (range, $0^{\circ}-45^{\circ}$ ) preoperatively compared with $17^{\circ}$ (range, $-5^{\circ}$ to $40^{\circ}$ ) postoperatively.

Two patients were classified as clinical failures based on poor mHHS or conversion to THA. One patient was a 29year-old man with no history of previous surgery, Stulberg Class II deformity, and a preoperative HHS of 48 . He developed a deep wound infection postoperatively requiring surgical débridement and THA 3 years later. A second patient was a 20 -year-old man with a history of Stulberg Class III with two previous femoral osteotomies. He had a poor clinical result despite good radiographic correction and a well-preserved joint space.

Reoperations included four patients with elective hardware removal. One patient developed recurrent hip pain. One year after the index surgery she underwent hardware removal and hip arthroscopy with psoas tendon lengthening, revision labral repair, and lysis of adhesions. She had a HHS of 100 points at 2-year followup. Major complications (Grade III and IV) [31, 34] occurred in two patients (two hips). One deep infection was treated with surgical débridement and antibiotics, whereas one superficial infection was treated with antibiotics alone. The deep infection went on to THA at 3 years (as described previously). The superficial infection resolved without surgery and the patient had an excellent outcome at 44 months (mHHS 96).

\section{Discussion}

Hip preservation surgery for Perthes-like deformities is challenging as a result of the combination of femoral, acetabular, and associated soft tissue abnormalities. The use of surgical hip dislocation as the primary means of treatment for symptomatic residual Perthes deformities has become more common $[1,3,7,14,15,25,28,30]$. Surgical dislocation simultaneously allows for assessment and treatment of intraarticular labrochondral pathology as well as biomechanical alteration of the hip with trochanteric advancement and relative femoral neck lengthening [1, 3, $28,30]$. The addition of a PAO to surgical dislocation for 
the treatment of Perthes-like deformities is more controversial, because the diagnosis of acetabular dysplasia (and associated structural instability) in residual Perthes deformities is less straightforward. Few studies have reports on the outcomes of combined surgical hip dislocation and PAO in these patients. We therefore evaluated a group of patients treated with this approach, focusing on (1) intraoperative findings; (2) radiographic correction; and (3) early patient-reported outcomes.

This study had several limitations. First, the requirements for multiple procedures in a single hip and lack of a control group make it difficult to determine the relative role of each portion of the procedure. However, previous reports of the treatment of Perthes-like deformities suggest that acetabular dysplasia may play a role in persistent symptoms after surgical treatment. Longer-term studies are needed to determine the long-term benefit of comprehensive deformity correction in this population. Second, the current study includes a small population treated with this combined approach at a single institution. Additionally, no current objective methods of defining structural instability in Perthes-like hips exist. Based on the experience of the senior authors, the subjective assessment of stability used in our study is a valuable intraoperative tool to confirm instability that is suspected preoperatively.

Intraarticular pathology was common in this study group with Perthes-like hip deformities and structural instability. Surgical hip dislocation remains a powerful tool to assess and treat intraoperative pathology. We previously reported outcomes of PAO for acetabular dysplasia associated with major aspherical femoral head deformities [9] and the outcomes of combined proximal femoral osteotomy and PAO for severe hip deformity [12]. Both studies demonstrated excellent short-term outcomes (HHS 61-86 and 6991, respectively). More recently, we have used the surgical dislocation approach for management of proximal femoral deformities. Although early outcomes of these distinct approaches appear to be similar, longer-term studies are needed.

Combined surgical hip dislocation and PAO improved radiographic indices of acetabular dysplasia. In our cohort, four patients had mild to moderate acetabular dysplasia (LCEA $16^{\circ}-25^{\circ}$ ), whereas the remainder had severe dysplasia $\left(\right.$ LCEA $\leq 15^{\circ}$ ). However, determination of the need for acetabular reorientation in these deformities can be challenging and should include preoperative radiographs, intraoperative assessment of joint stability, intraoperative radiographs, and intraoperative ROM examination [11, 29]. Intraoperative assessment after addressing the proximal femoral deformity is important and can reveal the presence of instability. Our intraoperative evaluation includes the assessment for subluxation in any one of three positions $\left(10^{\circ}\right.$ extension $/ 15^{\circ}$ external rotation; $45^{\circ}$ flexion $/ 20^{\circ}$ adduction/ $30^{\circ}$ internal rotation; $90^{\circ}$ flexion/neutral rotation) after confirmation of no extraarticular source of FAI-induced subluxation. In a hip demonstrating evidence of acetabular dysplasia/instability, intraoperative fluoroscopic evaluation in flexion, abduction, and internal rotation is used to confirm congruency. Finally, hip ROM must be adequate (flexion $\geq 90^{\circ}$, abduction $\geq 20^{\circ}$ ) to tolerate acetabular reorientation. Recommendations in the literature regarding the indication for PAO in Perthes-like hip deformities are inconsistent. Ganz et al. [14] recommended indications for PAO include a LCEA $<25^{\circ}, \mathrm{AI}>10^{\circ}$, or extrusion index $>30 \%$. Anderson et al. [2] recommended consideration for a PAO if LCEA $<16^{\circ}$. Albers et al. [1] found an AI of $>14^{\circ}$ to be a risk factor for a poor outcome. Two patients in their study underwent delayed PAO for unrecognized instability.

Early outcomes of combined surgical dislocation and PAO are encouraging and can be obtained with low complication rates. In the current study, two of 16 patients failed to improve with one clinical failure being directly attributable to a postoperative infection. In the remaining, 14 patient outcomes were excellent with an average mHHS of 93. Although long-term studies will be needed to determine the optimal treatment in this population, our early results appear to be similar to other reports in the literature. Albers et al. [1] reported minimum 5-year followup of a heterogeneous cohort of patients with residual Perthes disease. They recommended a PAO if the LCEA was $<25^{\circ}$. Their cohort included 11 patients undergoing combined surgical dislocation and PAO. They reported an $86 \%$ survival rate (revision and osteoarthritis-free) at 5 years and a $61 \%$ survival rate at 8 years. Detailed results of the combined PAO and surgical dislocation subgroup were not provided. Two patients required subsequent PAO for unrecognized instability at the time of the initial surgery. Major risk factors for poor outcome included acetabular dysplasia $\left(\mathrm{AI}>14^{\circ}\right)$. Shore et al. [30] reported outcomes of a cohort of 29 hips with residual Perthes deformities treated with surgical hip dislocation, including one patient undergoing additional staged PAO. At a mean followup of 3 years, they reported a $14 \%$ failure rate. The early outcomes of our study (HHS 61-87) are similar to those reported by Anderson et al. [3] (HHS 66-87). One patient in the Anderson et al. [3] study demonstrated lack of clinical improvement and underwent delayed PAO followed by an excellent clinical result. In a separate study, Anderson et al. [2] reported five cases of staged surgical dislocation and PAO, including two hips with Perthes-like deformities. In these two hips (one with mild to moderate dysplasia and one with severe acetabular dysplasia), patients had persistent symptoms after surgical dislocation and underwent subsequent PAO greater than 6 months later and resulted in excellent clinical results. As our experience has expanded, we have developed a preference for 
simultaneous rather than staged surgical dislocation and PAO (13 of 16 in this study). Together these procedures allow comprehensive deformity correction, intraarticular soft tissue procedures, dynamic joint assessment, and easier acetabular reorientation as a result of lack of mature scar tissue that can be encountered in staged procedures. In our series, we had an acceptable number of perioperative complications including two wound infections.

Outcomes of the current study demonstrate that patients undergoing combined surgical dislocation and PAO for symptomatic, residual Perthes-like deformities (with acetabular dysplasia) experience major clinical improvement at short-term evaluation while maintaining high activity level. Long-term studies of this and other surgical treatments for residual Perthes hip deformities are needed to establish the longevity and relative effectiveness of these treatment strategies.

\section{References}

1. Albers CE, Steppacher SD, Ganz R, Siebenrock KA, Tannast M. Joint-preserving surgery improves pain, range of motion, and abductor strength after Legg-Calve-Perthes disease. Clin Orthop Relat Res. 2012;470:2450-2461.

2. Anderson LA, Crofoot CD, Erickson JA, Peters CL. Staged surgical dislocation and redirectional periacetabular osteotomy: a report of five cases. J Bone Joint Surg Am. 2009;91:2469-2476.

3. Anderson LA, Erickson JA, Severson EP, Peters CL. Sequelae of Perthes disease: treatment with surgical hip dislocation and relative femoral neck lengthening. J Pediatr Orthop. 2010;30:758-766.

4. Aronson J. Osteoarthritis of the young adult hip: etiology and treatment. Instr Course Lect. 1986;35:119-128.

5. Beck M, Kalhor M, Leunig M, Ganz R. Hip morphology influences the pattern of damage to the acetabular cartilage: femoroacetabular impingement as a cause of early osteoarthritis of the hip. J Bone Joint Surg Br. 2005;87:1012-1018.

6. Beck M, Mast JW. The periacetabular osteotomy in Legg-Perthes-Like Deformities. Semin Arthroplasty. 1997;8:102-107.

7. Catterall A, Pringle J, Byers PD, Fulford GE, Kemp HB, Dolman CL, Bell HM, McKibbin B, Ralis Z, Jensen OM, Lauritzen J, Ponseti IV, Ogden J. A review of the morphology of Perthes' disease. J Bone Joint Surg Br. 1982;64:269-275.

8. Clohisy JC, Baca G, Beaule PE, Kim YJ, Larson CM, Millis MB, Podeszwa DA, Schoenecker PL, Sierra RJ, Sink EL, Sucato DJ, Trousdale RT, Zaltz I. Descriptive epidemiology of femoroacetabular impingement: a North American cohort of patients undergoing surgery. Am J Sports Med. 2013;41:1348-1356.

9. Clohisy JC, Barrett SE, Gordon JE, Delgado ED, Schoenecker PL. Periacetabular osteotomy for the treatment of severe acetabular dysplasia. J Bone Joint Surg Am. 2005;87:254-259.

10. Clohisy JC, Nunley RM, Curry MC, Schoenecker PL. Periacetabular osteotomy for the treatment of acetabular dysplasia associated with major aspherical femoral head deformities. J Bone Joint Surg Am. 2007;89:1417-1423.

11. Clohisy JC, Ross JR, North JD, Nepple JJ, Schoenecker PL. What are the factors associated with acetabular correction in Perthes-like hip deformities? Clin Orthop Relat Res. 2012;470:3439-3445.

12. Clohisy JC, St John LC, Nunley RM, Schutz AL, Schoenecker PL. Combined periacetabular and femoral osteotomies for severe hip deformities. Clin Orthop Relat Res. 2009;467:2221-2227.
13. Eijer H, Podeszwa DA, Ganz R, Leunig M. Evaluation and treatment of young adults with femoro-acetabular impingement secondary to Perthes' disease. Hip Int. 2006;16:273-280.

14. Ganz R, Horowitz K, Leunig M. Algorithm for femoral and periacetabular osteotomies in complex hip deformities. Clin Orthop Relat Res. 2010;468:3168-3180.

15. Ganz R, Huff TW, Leunig M. Extended retinacular soft-tissue flap for intra-articular hip surgery: surgical technique, indications, and results of application. Instr Course Lect. 2009;58:241-255.

16. Harris WH. Etiology of osteoarthritis of the hip. Clin Orthop Relat Res. 1986;213:20-33.

17. Herring JA, Kim HT, Browne R. Legg-Calve-Perthes disease. Part I: Classification of radiographs with use of the modified lateral pillar and Stulberg classifications. J Bone Joint Surg Am. 2004;86:2103-2120.

18. Heyman $\mathrm{CH}$, Herndon $\mathrm{CH}$. Legg-Perthes disease; a method for the measurement of the roentgenographic result. J Bone Joint Surg Am. 1950;32:767-778.

19. Ippolito E, Tudisco C, Farsetti P. The long-term prognosis of unilateral Perthes' disease. J Bone Joint Surg Br. 1987;69:243-250.

20. Joseph B. Morphological changes in the acetabulum in Perthes' disease. J Bone Joint Surg Br. 1989;71:756-763.

21. Kamegaya M, Shinada Y, Moriya H, Tsuchiya K, Akita T, Someya M. Acetabular remodelling in Perthes' disease after primary healing. J Pediatr Orthop. 1992;12:308-314.

22. Lecuire F. The long-term outcome of primary osteochondritis of the hip (Legg-Calve-Perthes' disease). J Bone Joint Surg Br. 2002;84:636-640.

23. McAndrew MP, Weinstein SL. A long-term follow-up of LeggCalve-Perthes disease. J Bone Joint Surg Am. 1984;66:860-869.

24. Mose K, Hjorth L, Ulfeldt M, Christensen ER, Jensen A. Legg Calve Perthes disease. The late occurence of coxarthrosis. Acta Orthop Scand Suppl. 1977;169:1-39.

25. Novais EN, Clohisy J, Siebenrock K, Podeszwa D, Sucato D, Kim YJ. Treatment of the symptomatic healed Perthes hip. Orthop Clin North Am. 2011;42:401-417, viii.

26. Omeroglu H, Ucar DH, Tumer Y. [A new measurement method for the radiographic assessment of the proximal femur: the center-trochanter distance] [in Turkish]. Acta Orthop Traumatol Turc. 2004;38:261-264.

27. Prather H, Harris-Hayes M, Hunt DM, Steger-May K, Mathew V, Clohisy JC. Reliability and agreement of hip range of motion and provocative physical examination tests in asymptomatic volunteers. $P M \&$ \& $2010 ; 2: 888-895$.

28. Rebello G, Spencer S, Millis MB, Kim YJ. Surgical dislocation in the management of pediatric and adolescent hip deformity. Clin Orthop Relat Res. 2009;467:724-731.

29. Ross JR, Nepple JJ, Baca G, Schoenecker PL, Clohisy JC. Intraarticular abnormalities in residual Perthes and Perthes-like hip deformities. Clin Orthop Relat Res. 2012;470:2968-2977.

30. Shore BJ, Novais EN, Millis MB, Kim YJ. Low early failure rates using a surgical dislocation approach in healed Legg-Calve-Perthes disease. Clin Orthop Relat Res. 2012;470:2441-2449.

31. Sink EL, Leunig M, Zaltz I, Gilbert JC, Clohisy J, Academic Network for Conservational Hip Outcomes Research Group. Reliability of a complication classification system for orthopaedic surgery. Clin Orthop Relat Res. 2012;470:2220-2226.

32. Snow SW, Keret D, Scarangella S, Bowen JR. Anterior impingement of the femoral head: a late phenomenon of LeggCalve-Perthes' disease. J Pediatr Orthop. 1993;13:286-289.

33. Stulberg SD, Cooperman DR, Wallensten R. The natural history of Legg-Calve-Perthes disease. J Bone Joint Surg Am. 1981;63:10951108.

34. Tannast M, Hanke M, Ecker TM, Murphy SB, Albers CE, Puls M. LCPD: reduced range of motion resulting from extra- and intraarticular impingement. Clin Orthop Relat Res. 2012;470:2431-2440. 
35. Tannast M, Macintyre N, Steppacher SD, Hosalkar HS, Ganz R, Siebenrock KA. A systematic approach to analyse the sequelae of LCPD. Hip Int. 2013;23(Suppl 9):S61-70.

36. Tönnis D. Congenital Dysplasia and Dislocation of the Hip in Children and Adults. Berlin, Germany; New York, NY, USA: Heidelberg, Springer; 1987.
37. Wiberg G. Studies on dysplastic acetabula and congenital sybluxation of the hip joint. With special reference to the complication of osteoarthritis. Acta Chir Scand Suppl. 1939; 58:7-38.

38. Yrjonen T. Long-term prognosis of Legg-Calve-Perthes disease: a meta-analysis. J Pediatr Orthop B. 1999;8:169-172. 